though the needs of these people are different from those of people with high risk behaviour.

These changing trends suggest a change in public awareness of HIV infection and the acquired immune deficiency syndrome (AIDS). This changed attitude coincided with and was presumably largely caused by a media campaign that took place during September to November 1986. In addition to the television and radio campaign most newspapers carried daily articles on AIDS and related issues. The intensification of the government's educational programme during the week of 23 November added to this momentum. The whole issue was catapulted into the public arena and worried people turned to clinics for sexually transmitted diseases for advice and reassurance. Given the sudden increase in workload, existing services were stretched to capacity, as reflected by the saturation of the services provided by health advisers. This necessitated an alteration in counselling procedures. Furthermore, HIV testing became more popular; fewer people were satisfied with counselling by itself, irrespective of their risk factors.

The observed increase in the number of people who requested HIV counselling and testing has been sustained beyond November 1986. Figure 2 shows the number of people tested between May 1986 and April 1987. The peak that was observed in March 1987 coincided with the AIDS campaign week. The relative lower numbers seen during December 1986 and January 1987 are partly explained by closure of the clinic over the Christmas holiday and during the freezing weather respectively. The drop in numbers seen during April 1987 coincided with reduced media coverage of AIDS.

Finally, the need to collect reliable data locally, regionally, and nationally cannot be overemphasised. Information is needed not only to assess the size of the problem but also to allow us to monitor trends over time. The effects of educational programmes can also be evaluated. Confidentiality, however, adds another dimension to the logistics of collecting such data. Given the current strain on existing services, the educational programmes will continue to add to the pressure on referral centres such as the Praed Street Clinic. More resources will be needed if the full preventive role of the campaign is to be fulfilled for those who seek counselling and testing. Furthermore, since patients who attended this clinic lived in more than one region the allocation of resources and the development of services should be planned within and among regions.

We thank all members of the Praed Street Clinic and departments of virology and community medicine who helped in the preparation of this paper. We thank especially Dr J Adams, Miss A Biro, Dr Y K Lau, Professor D Miller, and Mrs J Wadsworth for their help.

(Accepted 5 fune 1987)

\title{
HIV infection: increase in public awareness and anxiety
}

\author{
C SONNEX， ANNE PETHERICK， M W ADLER， D MILLER
}

\begin{abstract}
Between the end of September and mid-November 1986 the number of patients who requested antibody testing for human immunodeficiency virus (HIV) at this department increased by over $300 \%$. This increase followed a media campaign that emphasised the potential heterosexual spread of HIV. After pretest counselling roughly one quarter of the women and of the heterosexual men decided not to be tested. The reason given most often by women for testing was previous sexual intercourse with bisexual or possibly bisexual men. Heterosexual men were most often concerned about previous casual encounters or contact with prostitutes. Of the 641 tests for HIV antibody performed during the last three months of 1986, 37 (5.8\%) were positive.
\end{abstract}

Because an increasing number of patients are attending sexually transmitted diseases clinics for HIV antibody testing staffing levels in these clinics need to be reappraised now.

\section{Introduction}

Since the first case of the acquired immune deficiency syndrome (AIDS) was diagnosed in Britain in 1981 most of the general public

\footnotetext{
Academic Department of Genitourinary Medicine, Middlesex Hospital Medical School, London W1N 8AA

C SONNEX, MB, MRCP, lecturer in genitourinary medicine ANNE PETHERICK, RGN, research nurse

$M$ W ADLER, MD, FRCP, professor of genitourinary medicine

D MILLER, MD, DIPCLINPSYCH, senior clinical psychologist

Correspondence to: Professor Adler.
}

have thought of infection with human immunodeficiency virus (HIV) as a disease of homosexuals, intravenous drug abusers, and haemophiliacs. Heterosexuals have thought of themselves as not being at risk. An initial health education campaign by the government in March 1986 seemed to have little effect on improving public knowledge about AIDS. ${ }^{1}$

Those who work with HIV infection have always seen it as being sexually transmitted and thus have been fully aware of the potential heterosexual spread. The experience from Africa has strengthened this view. ${ }^{2}$ Despite the awareness by the medical profession, however, this message has been slow to filter through to the public.

In the last part of October 1986 several television programmes and newspaper articles appeared that emphasised the possibility of heterosexual spread of HIV. Not surprisingly, many heterosexual men and women began to wonder whether previous sexual relationships might have exposed them to HIV. The sudden increase in media coverage resulted in increasing numbers of people attending clinics for sexually transmitted diseases and requesting the "AIDS virus test."

To assess the extent of this "AIDS awareness" we analysed the number of clinic attenders who requested the HIV antibody test at the department of genitourinary medicine at this hospital from the end of September to the end of December 1986.

\section{Method}

People attending the clinic who request an HIV antibody test are initially counselled by either a doctor or a health adviser. This pretest counselling entails explaining the nature of the test and the meaning of a negative or positive result. The potential risk of infection and psychological stability are considered and discussed with the patient. A note is made by the doctor or health adviser of the sexual orientation of the patient and, when possible, the reason given for requesting the test. After pretest counselling many people 
do not wish to be tested, some require more time to consider the pros and cons, and others wish for immediate testing.

In most cases counselling is given by health advisers rather than doctors, and they use a standard schedule to record reasons for testing. Because of the increasing workload of health advisers, however, many doctors give counselling to men who attend. In many of these cases the reason for testing is not recorded in a standard way and sometimes not at all.

The numbers of patients who requested the HIV antibody test from 29 September to 31 December 1986 were analysed according to sexual orientation and whether or not testing was performed.

\section{Results}

During the three months $641 \mathrm{HIV}$ antibody tests were performed out of a total of 847 initial requests. The figure shows the increase in the numbers of people attending the clinic who requested the test in the last part of October and early November. Six heterosexual men requested antibody testing during the first week of the study (week ending 3 October). This number had increased to 35 in the week ending 21 November. Similarly, the number of women who requested the test increased from three a week to 24 a week over the same period. The number of homosexual men who attended for testing increased less dramatically but earlier, from 16 during the week ending 3 October to 36 during the last week of October.

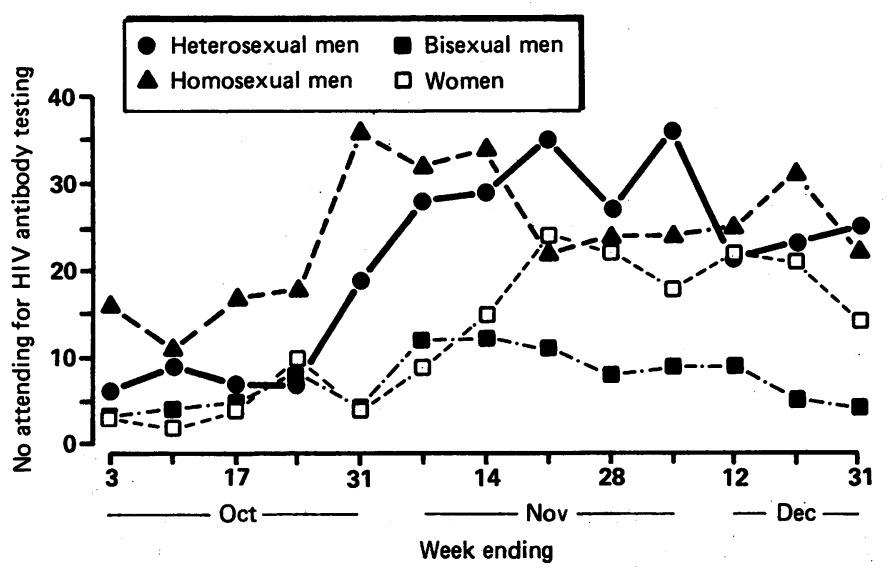

Numbers of people who requested HIV lesting at one clinic over three months.

Heterosexual men and women gave a variety of reasons for being tested (table). Of the 273 heterosexual men who requested testing, 192 were counselled by health advisers, who noted the reasons for testing. The remaining 81 were seen by doctors only, and the reason for testing was often not recorded. Forty eight $(28.5 \%)$ of the women were concerned about past relationships with bisexual or possibly bisexual men. Thirty five $(18 \cdot 2 \%)$ of the heterosexual men requested testing because of previous casual sexual encounters with women and $34(17 \cdot 7 \%)$ because of sex with prostitutes.

A total of $206(24.3 \%)$ patients decided against antibody testing after counselling: 61 of the 273 heterosexual men; 88 of the 312 homosexual men; 12 of the 94 bisexual men; and 45 of the 168 women. A slightly higher proportion of women than heterosexual men decided not to be tested $(26.8 \%$ compared with $22 \cdot 3 \%)$. Of the $641 \mathrm{HIV}$ antibody tests performed, $37(5 \cdot 8 \%)$ yielded positive results: $32(87 \%)$ of these were in homosexual men, two in heterosexual men, and three in bisexual men. None of the women was antibody positive.

\section{Discussion}

The sudden increase in the numbers of homosexual and heterosexual men requesting HIV antibody testing during the week ending 31 October is of interest. The number of women who requested the test increased slightly a week before this but then increased dramatically in mid-November. This delay is difficult to explain as greater public awareness from media coverage of AIDS would have been expected to produce more requests for tests in all groups simultaneously.
Although the publicity during October was concerned mostly with the potential heterosexual spread of HIV, greater numbers of homosexual men were also requesting the test. This is surprising as the homosexual population has been well informed about HIV antibody testing, and homosexuals have been attending clinics for sexually transmitted diseases for counselling and advice for a long time.

Reasons given by heterosexual men and by women for requesting HIV antibody testin between 29 September and 31 December 1986. (Only men who were counselled by health advisers are included)

\begin{tabular}{lr}
\hline & No $(\%)$ \\
\hline Heterosexual men (n=192): & \\
Vaginal intercourse with several casual contacts & $35(18 \cdot 2)$ \\
Vaginal intercourse with prostitutes & $34(17 \cdot 7)$ \\
Intravenous drug misusers & $23(12 \cdot 0)$ \\
Vaginal intercourse with an African & $17(8 \cdot 9)$ \\
Vaginal intercourse with an intravenous drug misuser & $11(5 \cdot 7)$ \\
Vaginal intercourse with an American & $10(5 \cdot 2)$ \\
No specific reason given & $10(5 \cdot 2)$ \\
Girlfriend had had vaginal intercourse with a bisexual & 9 \\
Vaginal intercourse with a woman from the Far East & $7(3 \cdot 6)$ \\
Vaginal intercourse with a possible intravenous drug misuser & $4(2 \cdot 1)$ \\
Previous blood transfusion & $1(0 \cdot 5)$ \\
Miscellaneous & $31(16 \cdot 2)$ \\
Women (n=168): & \\
Vaginal intercourse with a bisexual man & $32(19 \cdot 0)$ \\
Vaginal intercourse with a possible bisexual man & $16(9 \cdot 5)$ \\
Vaginal intercourse with an intravenous drug misuser & $14(8 \cdot 3)$ \\
Several casual male sexual partners in past & $12(7 \cdot 1)$ \\
Vaginal intercourse with an African & $11(6 \cdot 5)$ \\
Boyfriend is promiscuous & $10(6 \cdot 0)$ \\
No specific reason given & $9(5 \cdot 4)$ \\
Vaginal intercourse with a foreign man (not included in this list) & $7(4 \cdot 2)$ \\
Prostitute & $5(3 \cdot 0)$ \\
Vaginal intercourse with a possible intravenous drug misuser & $5(3 \cdot 0)$ \\
Intravenous drug misuser & $4(2 \cdot 4)$ \\
Vaginal intercourse with an American & $3(1 \cdot 8)$ \\
Vaginal intercourse with a man from the Far East & $3(1 \cdot 8)$ \\
Previous blood transfusion & $2(1 \cdot 2)$ \\
Boyfriend had had vaginal intercourse with prostitutes & $2(1 \cdot 2)$ \\
Rape victim & $2(1 \cdot 2)$ \\
Miscellaneous & $31(18 \cdot 4)$ \\
&
\end{tabular}

*Men: at minimal or no risk of exposure-for example, social or occupational contact with people from high risk groups, insect bites while travelling abroad, rumours that the family people from high risk groups, insect bites while travelling abroad, rumours that the family
butcher had AIDS, etc. Women: mostly low risk activities-for example, social contact with butcher had AIDS, etc. Women: mostly low risk activities-for example, social contact with
homosexual or bisexual men, kissing men from high risk groups, insect bites while travelling homosexual or

Roughly one quarter of heterosexual men and women who initially inquired about antibody testing decided against the test after counselling. The clinic notes suggested that most of these were at minimal risk of exposure and showed disproportionate anxiety about AIDS owing to lack of knowledge about HIV infection. Past contact with prostitutes or casual girlfriends arouses feelings of guilt and anxiety in many heterosexual men and accounted for over one third of requests.

The clinic is in the west end of London, an area with a large population of drug misusers. It was therefore of no surprise but encouraging that $23(12 \%)$ of the requests from heterosexual men came from injecting drug users. Many women (28.5\%) were convinced or suspected that previous boyfriends had been bisexual. On further questioning, however, most of these suspicions seemed unfounded, and anxiety was usually allayed after counselling. A smaller percentage of women than men were drug users $(2 \cdot 4 \%)$, but $14(8 \%)$ of the women were concerned because of previous sexual intercourse with male drug users. Compared with the other three groups a much smaller proportion of bisexual men decided not to be tested after counselling. Most were fully aware of the potential danger to women with whom they had had sexual intercourse and felt a strong need to know whether they were carrying HIV.

Of the 37 patients who were positive for HIV, two were heterosexual men and three were bisexual men. This is somewhat concerning and emphasises the potential spread into the heterosexual community. One of the antibody positive heterosexual men seemed to have contracted the infection after vaginal intercourse with a prostitute in Zimbabwe. He denied having had a blood 
transfusion or injections, and there was no history of venereal infection or genital ulceration. The other antibody positive heterosexual man was an intravenous drug user.

When the beginning of October was compared with midNovember there was an increase of over $300 \%$ in people attending the clinic who required counselling for the HIV antibody test. By the end of December this had fallen slightly, but with the surge in publicity at the end of February we are expecting a further dramatic increase in requests for testing. Our clinic staff, in particular the health advisers, are working under enormous pressure at present. We do not foresee our workload decreasing, rather the opposite. The recent increase in public awareness and anxiety about AIDS, which will probably continue with further public health education, surely indicates that it is time for an urgent reappraisal of staffing levels in clinics for sexually transmitted diseases.

\section{References}

1 Mills S, Campbell MJ, Waters WE. Public knowledge of AIDS and the DHSS advertisement campaign. Br Med f 1986;293:1089-90.

2 Quinn TC, Mann JM, Curran JW, Piot P. AIDS in Africa: an epidemiologic paradigm. Science 1986;234:955-63.

(Accepted 5 fune 1987)

\title{
Medical History
}

\section{Jeremy Bentham's self image: an exemplary bequest for dissection}

\author{
RUTH RICHARDSON， BRIAN HURWITZ
}

The eighteenth century philosopher and law reformer Jeremy Bentham still sits above ground, in his Sunday best. He died in 1832 and, in keeping with his doctrine of Utility, left his body for dissection. He expected to gain deathbed comfort from the thought that: "How little service soever it may have been in my power to render to mankind during my lifetime, I shall at least be not altogether useless after my death."

But this was to be no ordinary bequest for dissection. Bentham conceived that a corpse had twofold use-value-transitory: "anatomical, or dissectional"; and more permanent: "conservative, or statuary." The "savage ingenuity" of the indigenous New Zealanders had inspired Bentham to direct that his head be dried and preserved. ${ }^{2}$ During his lifetime experiments were made using the oven at Bentham's own house. ${ }^{3}$ His skeleton was to be reassembled, fully clothed, and exhibited in a glass case. This reconstructed entity he termed his auto-icon, or self image. For the previous 20 years the grand old man had carried in his pocket the glass eyeballs which would adorn his dehydrated head. ${ }^{4}$

\section{Bodies for anatomical inquiry}

To ensure that his plan would be adopted Bentham arranged to bequeath his body to his "dear friend" Dr Thomas Southwood Smith, author of an influential article "Use of the dead to the living," which had appeared in the Westminster Review in $1824 .^{5}$ At the time anatomy was in bad repute as a result of widespread grave robbery. There existed no legal source of bodies for dissection other than those of hanged murderers. In all but the most

Institute of Historical Research, University of London, London WC1E 7HU RUTH RICHARDSON, MA, DPHIL, historian

London $\mathbf{N 1}$

BRIAN HURWITZ, MRCP, MRCGP, general practitioner

Correspondence to: Dr Richardson. enlightened circles dissection was deeply feared, regarded by law since Tudor times as a fate worse than death. ${ }^{6}$

Southwood Smith's theme had been the immeasurable utility of anatomical knowledge. He highlighted its value in diagnosis and treatment. An anatomical understanding of referred pain would ensure, for example, that irrelevant operations would not be attempted in cases of right shoulder tip or referred knee pain. Only by close study of "this curious and complicated machine," the human body, could commonly performed surgery, such as amputation and hernia repair, be safely undertaken. His argument remains unanswerable:

Disease, which it is the object of these arts to prevent and to cure, is denoted by disordered function: disordered function cannot be understood without a knowledge of healthy function; healthy function cannot be understood without a knowledge of structure; structure cannot be understood unless it be examined.?

Who, then, would provide subjects for anatomical inquiry: the living or the dead, the rich or the poor? A public choice must be made: allow the dissection of the dead or accept that surgeons would otherwise be driven to obtain knowledge by practising on the bodies of the living. The social implications of adopting the latter course were stark. The rich, Southwood Smith pointed out, would always have it in their power to select experienced surgeons. Such a choice was not available to the poor. Public hospitals and poorhouses would therefore be converted "into so many schools where the surgeon by practising on the poor would learn to operate on the rich with safety and dexterity." ${ }^{8}$ In 1824 the resolution to this problem was clear to Southwood Smith: the unclaimed dead from poorhouses and hospitals must be requisitioned for dissection. "If the dead bodies of the poor are not appropriated to this use, their living bodies will and must be."

\section{Bentham's decision}

Jeremy Bentham had decided to bequeath his body for dissection in 1769 when he was 21 , over half a century before Southwood Smith's article. Undoubtedly, Bentham intended by his example to promote bequests for anatomy. Yet he was certainly influenced by Southwood Smith. Within two years of the publication of "Use of the dead to the living," Bentham drafted legislation-which was to provide a basis for the 1832 Anatomy Act-along the very lines suggested. ${ }^{9}$

In the eight years between 1824 and 1832 the climate of opinion changed 